\title{
IMPLEMENTASI METODE DMAIC (DEFINE, MEASURE,ANALYZE, IMPROVE, CONTROL) UNTUK MENURUNKAN CACAT BONDING SEPATU DI GEDUNG 2 (DUA) PADA PT. PARKLAND WORLD INDONESIA.
}

\author{
Suci Terawati ${ }^{1}$, Wahyu Wiguna ${ }^{2}$ \\ ${ }^{1,2}$ Universitas Bina Bangsa \\ sucitera97@gmail.com
}

\begin{abstract}
ABSTRAK
Studi ini menfokuskan bagaimana bisa mengendalikan cacat produk di PT. Parkland World Indonesia, perusahaan yang bergerak di bidang industri sepatu merek Adidas periode Apri 2020 sampai dengan Maret 2021 rata-rata kecacatan produk mencapai 8.37\%, sementara perusahaan menginginkan Zero Defect. Tujuan dari penelitian ini adalah untuk menurunkan cacat bonding melalui pendekatan kualitatif, dimana kami mengamati dan melakukan pengujian guna untuk meningkatkan peforma dan menurunkan kecacatan. Metode untuk menjamin kualitas dari produk yang di hasilkan adalah DMAIC (Define, Measure, Analyze, Improve, Control) merupakan pendekatan penyelesaian masalah berbasis data yang membantu untuk melakukan perbaikan secara optimal sehingga cacat yang disebabkan proses produksi bisa menurun. Hasil dari data yang telah dianalisis menunjukkan 5 CTQ (Critical to Quality) bonding yaitu dengan persentase tertinggi pada bonding stabilizer sebesar $43.70 \%$. Kesimpulan yang dapat diambil dari penelitian ini adalah penyebab kecacatan bonding pada sepatu bisa dilakukan pencegahan dengan menerapkan beberapa usulan perbaikan, dengan cara menyediakan SOP terbaru, visual standar maksimal WIP, visual sistem pergantian sikat, dan menyediakan board meeting RCA (root cause analysis).
\end{abstract}

Kata kunci : DMAIC, CTQ, Quality

\section{ABSTRACT}

This study focuses on how to control defective products at PT. Parkland World Indonesia, a company engaged in the Adidas brand shoe industry for the period April 2020 to March 2021, the average product achievement reaches $8.37 \%$, while the company wants Zero Defect. The purpose of this study is to reduce bond defects through an approximation approach, where we observe and conduct tests in order to improve performance and reduce. The method to guarantee the quality of the product produced is DMAIC (Define, Measure, Analyze, Improve, Control) which is a data-based problem solving approach that helps to optimally correct defects caused by the production process can decrease. The results of the analyzed data showed 5 CTQ (Critical to Quality) bonds with the highest percentage of bonding stabilizer at 43.70\%. The conclusions and recommendations that can be drawn from this study are the causes of shoe ties that can be prevented by implementing several proposed improvements, by providing the latest SOPs, maximum WIP visual standards, brush change visual systems, and providing RCA (root cause analysis) board meetings.

Keywords : DMAIC, CTQ, Quality 
Pertumbuhan ilmu pengetahuan serta teknologi yang sangat pesat, yang diterapkan di bidang industri manufaktur bisa menyebabkan perubahan- perubahan berarti dalam dunia industri. Pergantian dunia industri berakibat pada persaingan yang kompetitif antara industri yang satu dengan yang lain. Untuk itu, perencanaan yang baik butuh dilakukan oleh industri pada berbagai perencanaan fasilitas- fasilitas produksi yang lain meliputi mesin, tenaga kerja, dan peralatan produksi.

Aktivitas produksi pada industri manufaktur ialah sesuatu aktivitas yang sangat penting. Apalagi dalam berbagai pembicaran, dikatakan kalau produksi ialah dapurnya industri tersebut. Apabila pada aktivitas produksi ada berbagai hambatan, hingga memunculkan bermacam kerugian baik material ataupun unmaterial. Sehingga dibutuhkan pengendalian kualitas dalam industri untuk memenuhi standar kualitas yang sudah ditetapkan sebelumnya.

Pengertian kualitas menurut Handoko merupakan suatu faktor yang terdapat dalam suatu produk yang dapat menyebabkan produk tersebut bernilai sesuai dengan maksud untuk apa produk tersebut di produksi. Masalah jaminan kualitas produk menjadi hal yang sangat penting, yaitu sebagai senjata utama untuk mencapai tujuan utama perusahaan, karena dengan kualitas produk yang baik akan meningkatkan kepuasan dan loyalitas konsumen.

PT. Parkland World Indonesia merupakan perusahaan yang bergerak di bidang garmen, yang terkhusus memproduksi sepatu dengan merek Adidas. Permintaan pasar terhadap produksi sangatlah besar sehingga PT. Parkland World Indonesia harus selalu berusaha agar produksinya dapat ditingkatkan dengan kualitas sebagaimana yang diharapkan. Untuk dapat menghasilkan kualitas yang baik maka perlu adanya peningkatan dari berbagai hal misalnya, masalah yang menyangkut penyediaan penggunaan barang, pengurusan dan penempatan tenaga kerja, pemanfaatan sarana dan prasarana produksi, serta penyempurnaan metode kerja yang baik. Jika hal tersebut dijalankan oleh perusahaan maka produk yang dihasilkan dapat selesai tepat waktu dengan kualitas yang bagus..

PT. Parkland World Indonesia memandang bahwa kualitas sebagai faktor kunci yang membawa keberhasilan, untuk itulah pengendalian kualitas merupakan jaminan produk perusahaan dengan tujuan produk yang dihasilkan memenuhi spesifikasi atau standar mutu yang telah ditetapkan oleh buyer maupun perusahaan. Melalui inspeksi secara periodik selama proses produksi berlangsung dan melakukan tindakan korektif pada hasil produksi maka hal itu dapat menekan jumlah produk yang rusak dan menjaga agar produk akhir sesuai dengan standar kualitas yang diinginkan buyer maupun perusahaan. Berikut ini akan disajikan data empiris 
Prosiding The 1st National Conference on Applied Business, Education, \& Technology (NCABET)"

Unversitas Bina Bangsa 2021

DOI Article : 10.46306/ncabet.v1i1.36

pemeriksaan produk sepatu Adidas di PT. Parkland World Indonesia dari bulan April 2020 sampai Maret 2021.

Tabel 1. Data Produksi dan Jumlah Defect Sepatu di Gedung 2 (Dua)

PT. Parkland World Indonesia.

\begin{tabular}{|c|l|c|c|c|}
\hline No & Periode & Jumlah Produksi & $\begin{array}{c}\text { Jumlah } \\
\text { Defect }\end{array}$ & Rate Defect \\
\hline 1 & Apr-20 & 198.040 & 14.667 & $7,41 \%$ \\
\hline 2 & Mei-20 & 200.450 & 16.821 & $8,39 \%$ \\
\hline 3 & Jun-20 & 205.643 & 18.811 & $9,15 \%$ \\
\hline 4 & Jul-20 & 184.004 & 21.053 & $11,44 \%$ \\
\hline 5 & Agt-20 & 217.160 & 22.533 & $10,38 \%$ \\
\hline 6 & Sep-20 & 210.692 & 18.444 & $8,75 \%$ \\
\hline 7 & Okt-20 & 210.401 & 12.981 & $6,17 \%$ \\
\hline 8 & Nov-20 & 198.839 & 15.657 & $7,87 \%$ \\
\hline 9 & Des-20 & 248.894 & 20.393 & $8,19 \%$ \\
\hline 10 & Jan-21 & 226.511 & 18.932 & $8,36 \%$ \\
\hline 11 & Feb-21 & 192.355 & 14.023 & $7,29 \%$ \\
\hline 12 & Mar-21 & 267.591 & 20.115 & $7,52 \%$ \\
\hline TOTAL & & 2.560 .580 & 214.430 & $8,37 \%$ \\
\hline Sumber $:$ PT & Parkland & Orld & \\
\hline
\end{tabular}

Sumber : PT. Parkland World Indonesia

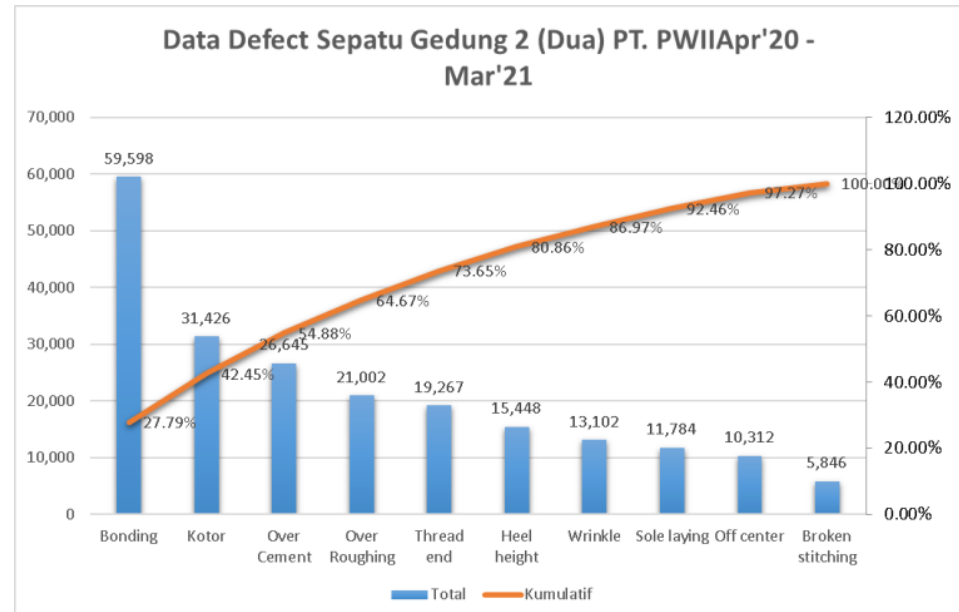

Gambar 1. Data Jenis Defect Gedung 2 (Dua) di PT. Parkland World Indonesia

Berdasarkan tabel dan gambar di atas dapat diketahui besaran produk cacat yang terdapat pada produksi sepatu di gedung 2 (dua) PT. Parkland World Indonesia masih terbilang cukup besar. Dari sepuluh cacat sepatu yang sering muncul di area produksi, cacat paling besar dari diagram pareto di atas adalah cacat jenis bonding. Cacat di PT. Parkland World Indonesia menjadi tanggung jawab perusahaan, lebih tepatnya disebut sebagai kerugian perusahaan karena rata-rata barang cacat disebabkan oleh pihak dalam perusahaan, bukan dari supplier. Cacat ini dapat disebabkan oleh kecerobohan karyawan, karena kerusakan mesin yang digunakan sehingga barang rusak, dan bisa juga karena kesalahan teknik produksinya. 
Prosiding The 1st National Conference on Applied Business, Education, \& Technology (NCABET)"

Unversitas Bina Bangsa 2021

DOI Article : 10.46306/ncabet.v1i1.36

Berkurangnya produk cacat tentu akan menghemat biaya karena jumlah bahan baku yang diolah dapat dimaksimalkan. Tidak perlu ada sepatu hasil produksi yang dihancurkan akibat tidak sesuai dengan standar yang diharapkan. Hal ini juga tentu berhubungan dengan produktivitas. Jadi dapat disimpulkan bahwa dengan pengaplikasian quality control yang baik, PT. Parkland World Indonesia akan mampu mengefisienkan biaya dan meningkatkan produktivitas. Selain itu, dalam memenuhi keinginan buyer terhadap produk yang diinginkan, perusahaan tidak akan mengalami kesulitan karena kualitas produk merupakan faktor dasar keputusan buyer dalam memilih dan menilai suatu produk.

Hal ini membuat peneliti tertarik untuk melakukan penelitian mengenai masalah yang dihadapi oleh PT. Parkland World Indonesia dengan mengangkat tema kecacatan produk dengan presentasi cacat produk tertinggi, yaitu bonding. Ada berbagai macam metode yang bermanfaat di dalam pengendalian kualitas. Salah satunya dengan melakukan metode Define, Measure, Analyze, Improve, Control (DMAIC). Metode DMAIC merupakan pendekatan yang lengkap untuk melakukan pengendalian dan perbaikan kualitas karena dimulai dengan mengidentifikasi masalah sampai melakukan pengendalian serta memberi usulan untuk melakukan perbaikan.

Langkah pertama dalam proses metode DMAIC adalah perumusan define yang mencakup pemilihan masalah yang harus diatasi, menemukan kesepakatan untuk melakukan perbaikan serta pemahaman proses yang terlibat. Pada tahap ini akan menentukan apa yang terjadi Critiqal To Quality (CTQ) yang akan menjadi tujuan dilakukannya perbaikan. Selanjutnya tahap pengukuran atau measure, pada tahap ini terlebih dahulu manajemen harus memahami proses internal yang potensial sangat berpengaruh terhadap kualitas output Critiqal To Quality. Selanjutnya tahan analyze, hal yang dilakukan dalam tahap ini adalah meningkatkan pemahaman dalam tim manajemen untuk mengidentifikasi masalah dengan menggunakan analisa yang menenteukan akar masalah yang terjadi. Kemudian improve, pada tahap ini manajemen memastikan variabel - variabel kunci atau faktor utama yang mengukur daya pengaruh terhadap hasil yang diinginkan. Tahap terakhir adalah control, tahap ini untuk memastikan agar perbaikan selama proses produksi tetap terjaga melalui pemantauan baseline kinerja utama. Tahap ini perlu tindakan dan pengawasan selama produksi, atau koreksi untuk mengatasi masalah. 


\section{METODOLOGI PENELITIAN}

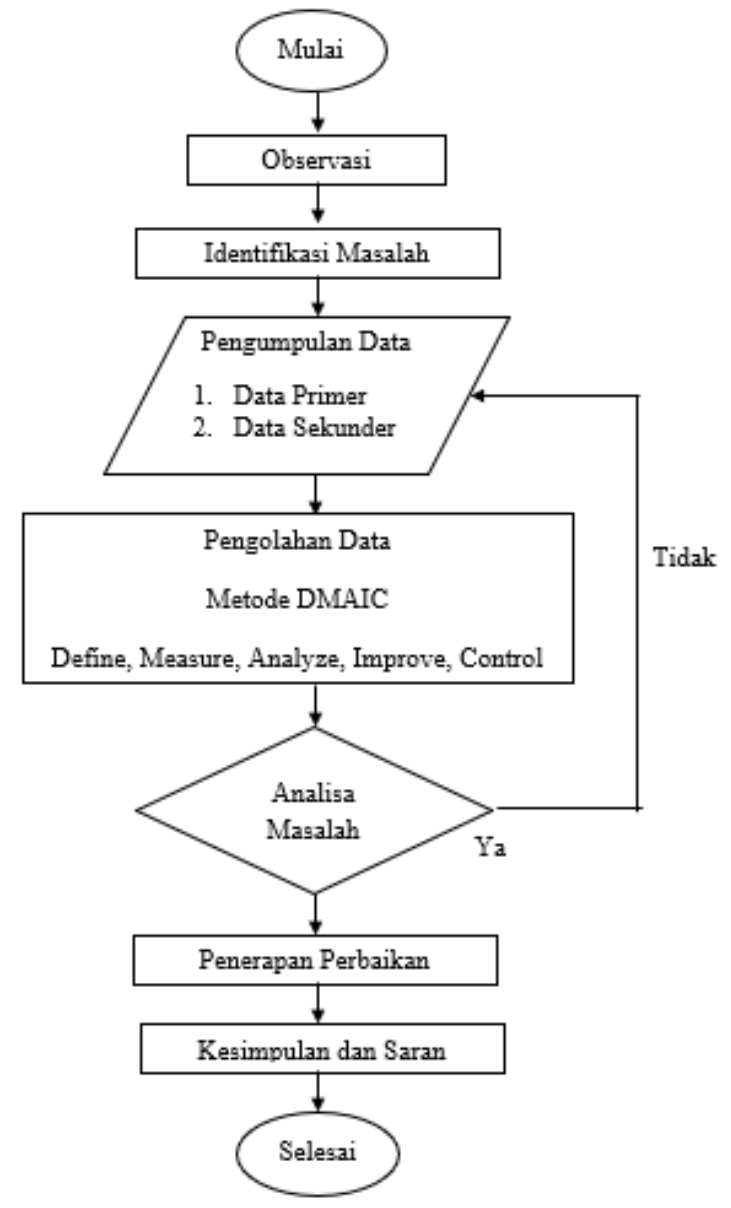

Gambar 2. Diagram Alir Penelitian

Peneliti melakukan observasi pada area produksi terkait pengendalian kualitas yang dilakukan.

a. Identifikasi Masalah

Peneliti melakukan penentuan terhadap masalah yang akan diperbaiki setelah melakukan observasi di area produksi terkait pengendalian kualitas.

b. Pengumpulan Data

Peneliti melakukan pengumpulan data berupa data output produksi dan data produk cacat berdasarkan laporan dari Quality Departement dan melakukan wawancara kepada Building Manager, QIP Head Building dan juga bagian yang berperan dalam area produksi.

c. Pengolahan Data dari Metode DMAIC

Peneliti melakukan pengolahan data menggunakan metode DMAIC (Define, Measure, Analyze, Improve, Control) terhadap pengendalian kualitas bonding di perusahaan. Adapun penjelasan mengenai pendekatan DMAIC adalah sebagai berikut :

1) Define (mendefinisikan) yaitu langkah operasional pertama dalam program peningkatan kualitas Six Sigma. Dalam tahap define dilakukan identifikasi proyek yang potensial, mengidentifikasi karakteristik kualitas kunci (CTQ). 
2) Measure (mengukur) yaitu langkah operasional kedua dalam proses peningkatan kualitas dan merupakan sebuah jembatan langkah berikutnya.

3) Analyze (menganalisa) yaitu tahap dilakukannya penentuan sebab akibat dari suatu permasalahan yang memahami adanya berbagai sumber variasi dari data yang didapatkan pada tahap measure.

4) Improve (memperbaiki) Pada tahap ini dirancang usulan-usulan perbaikan untuk mengurangi cacat yang terjadi. Pada tahap ini pula dilakukan implementasi usulan-usulan yang telah dirancang.

5) Control (mengendalikan) langkah operasional terakhir untuk membuat rencana pengendalian proses dan prosedur-prosedur agar perbaikan dapat terus terlaksana. Pada tahap ini hasil peningkatan kualitas didokumentasikan dan disebarluaskan, praktik-praktik terbaik yang sukses dalam peningkatan proses distandarisasikan dan disajikan sebagai pedoman standar, serta kepemilikan atau tanggung jawab ditransfer dari tim kepada pemilik atau penanggung jawab proses.

d. Analisa Masalah

Peneliti melakukan analisa terhadap faktor-faktor penyebab permasalahan yang menimbulkan produk cacat.

e. Penerapan Perbaikan

Peneliti melakukan perbaikan terkait permasalahan pengendalian kualitas menggunakan metode DMAIC.

f. Kesimpulan dan Saran

Peneliti memberikan kesimpulan dan saran terkait penyelesaian permasalahan kepada pihak perusahaan yang dapat di implementasikan sebagai acuan dalam pengendalian kualitas.

\section{HASIL DAN PEMBAHASAN}

\section{Data Cacat Bonding}

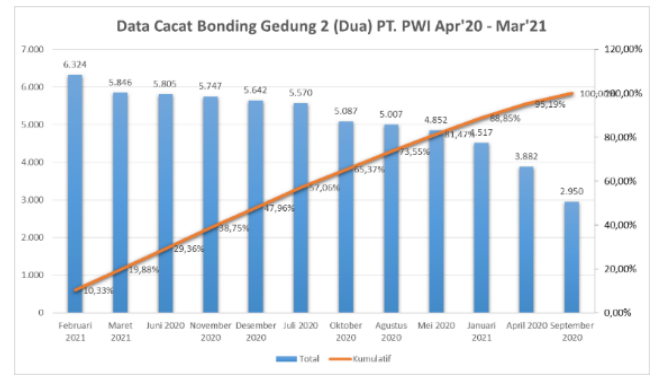

Gambar 3. Data Cacat Bonding Bulan April 2020 - Maret 2021 
Prosiding The 1st National Conference on Applied Business, Education, \& Technology (NCABET)"

Unversitas Bina Bangsa 2021

DOI Article : 10.46306/ncabet.v1i1.36

Define (Critical to Quality)

Tahap awal dalam pendekatan DMAIC adalah identifikasi hal-hal terkait kualitas yang menjadi prioritas (critical to quality), yaitu bonding stabilizer, bonding outsole, bonding flexing, bonding toe cap, dan bonding heel.

Tabel 2 Data Jenis Cacat Bonding Bulan April 2020 - Maret 2021

\begin{tabular}{|l|c|c|}
\hline \multicolumn{1}{|c|}{ Jenis Defect } & Total & $\%$ \\
\hline Bonding Stabilizer & 26,755 & $43.70 \%$ \\
\hline Bonding Outsole & 11,231 & $18.34 \%$ \\
\hline Bonding Flexing & 9,845 & $16.08 \%$ \\
\hline Bonding Toe Cap & 7,717 & $12.60 \%$ \\
\hline Bonding Heel & $\mathbf{5 , 6 8 1}$ & $9.28 \%$ \\
\hline TOTAL & 61,229 & $100.00 \%$ \\
\hline
\end{tabular}

Sumber : PT. Parkland World Indonesia

\section{Measure (Diagram Pareto)}

Dalam tahapan DMAIC yang kedua ini bertujuan untuk mengetahui kategori produkproduk cacat yang terjadi selama proses produksi. Berdasarkan analisis dari diagram pareto, diketahui bahwa kategori cacat bonding stabilizer menjadi jenis cacat bonding tertinggi dengan presentasi sebesar $43.70 \%$.

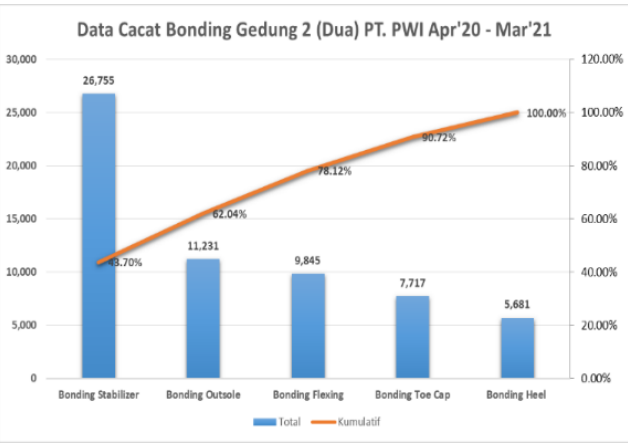

Gambar 4. Data Jenis Cacat Bonding Bulan April 2020 - Maret 2021

Sumber : PT. Parkland World Indonesia

\section{Analyze (Diagram Sebab dan Akibat)}

Pada tahap analyze melakukan analisa menggunakan diagram sebab-akibat ditemukan penyebab utama kecacatan ada 4 faktor yaitu, man, machine, method, measurement. Faktorfaktor yang menjadi penyebab terjadinya cacat bonding adalah operator tidak konsisten dalam 
proses lem upper ke outsole, pemakaian tooling tidak sesuai dengan SOP, aplikasi proses lem upper ke outsole kurang tebal dan tidak rata, dan yang terakhir terlalu banyak WIP di tempat kerja.

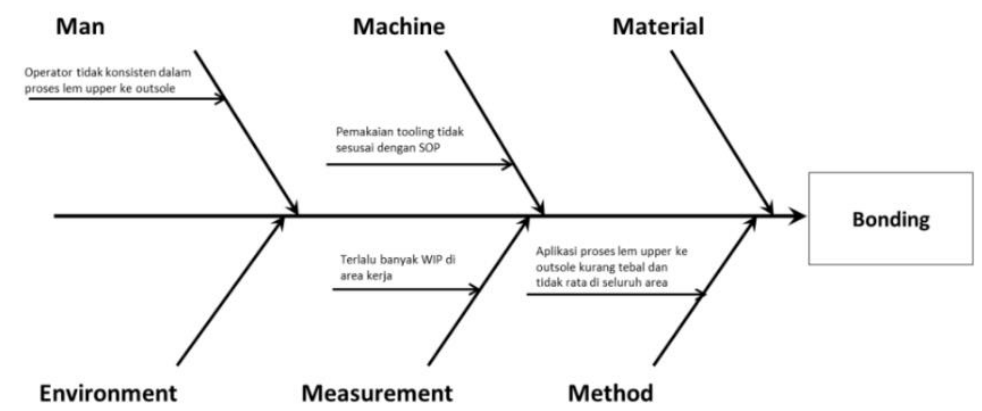

Gambar 5. Diagram Sebab dan Akibat

\section{Improve $(\mathbf{5 W}+\mathbf{1 H})$}

Tahap improve pada tahap ini untuk merencanakan penanggulangan cacat yang terjadi pada produk adalah cacat bonding dapat dilakukan dengan metode $5 \mathrm{~W}+1 \mathrm{H}$ (What, Why, When, Where, Who, How)

Tabel 3. Perbaikan Melalui $5 \mathrm{~W}+1 \mathrm{H}$

\begin{tabular}{|c|c|c|c|c|c|c|c|}
\hline \multirow[b]{2}{*}{$\begin{array}{c}\text { FAKTOR } \\
\text { DOMINAN }\end{array}$} & \multirow[b]{2}{*}{$\begin{array}{l}\text { PENYEBAB } \\
\text { DOMINAN }\end{array}$} & WHY & WHAT & WHERE & WHEN & WHO & HOW \\
\hline & & $\begin{array}{c}\text { Mengapa perlu } \\
\text { diperbaiki? }\end{array}$ & $\begin{array}{c}\text { Apa rencana } \\
\text { perbaikannya? }\end{array}$ & $\begin{array}{c}\text { Di mana } \\
\text { perbaikan } \\
\text { dilakukan }\end{array}$ & $\begin{array}{c}\text { Kapan } \\
\text { perbaikan } \\
\text { dilakukan }\end{array}$ & $\begin{array}{l}\text { Siapa pelaku } \\
\text { perbaikan }\end{array}$ & $\begin{array}{l}\text { Bagaimana } \\
\text { cara } \\
\text { perbaikan? }\end{array}$ \\
\hline Manusia & $\begin{array}{l}\text { Operator } \\
\text { tidak } \\
\text { melakukan } \\
\text { self } \\
\text { inspection }\end{array}$ & $\begin{array}{l}\text { Agar operator } \\
\text { konsisten } \\
\text { melakukan self } \\
\text { inspection }\end{array}$ & $\begin{array}{l}\text { Melakukan } \\
\text { training }\end{array}$ & Di area produksi & $\begin{array}{l}\text { Mei } 2021 \text { - Juli } \\
2021\end{array}$ & $\begin{array}{l}\text { Tim Produksi, } \\
\text { IE, QIP, dan } \\
\text { PTT }\end{array}$ & $\begin{array}{c}\text { Melakukan } \\
\text { training SOP } \\
\text { untuk operator }\end{array}$ \\
\hline Mesin & $\begin{array}{c}\text { Tidak ada } \\
\text { kontrol sistem } \\
\text { dalam } \\
\text { pergantian } \\
\text { sikat }\end{array}$ & $\begin{array}{c}\text { Agar ada kontrol } \\
\text { sistem untuk } \\
\text { pergantian sikat }\end{array}$ & $\begin{array}{c}\text { Membuat sistem } \\
\text { daftar periksa } \\
\text { harian }\end{array}$ & Di area produksi & $\begin{array}{l}\text { Mei } 2021 \text { - Juli } \\
2021\end{array}$ & $\begin{array}{l}\text { Tim Produksi, } \\
\text { Lab, QIP, dan } \\
\text { PTT }\end{array}$ & $\begin{array}{c}\text { Membuat sistem } \\
\text { daftar periksa } \\
\text { harian pergantian } \\
\text { sikat }\end{array}$ \\
\hline Metode & $\begin{array}{c}\text { Aplikasi } \\
\text { proses lem } \\
\text { upper ke } \\
\text { outsole kurang } \\
\text { tebal dan tidak } \\
\text { rata di seluruh } \\
\text { area }\end{array}$ & $\begin{array}{c}\text { Agar tidak } \\
\text { ditemukan } \\
\text { bonding pada } \\
\text { sepatu }\end{array}$ & $\begin{array}{c}\text { Menggunakan } \\
\text { tooling sebagai } \\
\text { penanda lem } \\
\text { telah } \\
\text { diaplikasikan } \\
\text { sesuai standar }\end{array}$ & Di area produksi & $\begin{array}{l}\text { Mei } 2021 \text { - Juli } \\
2021\end{array}$ & $\begin{array}{l}\text { Tim Produksi, } \\
\text { Lab, QIP, dan } \\
\text { PTT }\end{array}$ & $\begin{array}{l}\text { Mengaplikasikan } \\
\text { blue lamp pada } \\
\text { mesin conveyer }\end{array}$ \\
\hline Measurement & $\begin{array}{c}\text { Terlalu banyak } \\
\text { WIP di area } \\
\text { kerja }\end{array}$ & $\begin{array}{c}\text { Agar tidak } \\
\text { terjadi } \\
\text { penumpukan } \\
\text { atau over WIP }\end{array}$ & $\begin{array}{c}\text { Membuat } \\
\text { standar sistem di } \\
\text { area kerja }\end{array}$ & Di area produksi & $\begin{array}{l}\text { Mei } 2021 \text { - Juli } \\
2021\end{array}$ & $\begin{array}{l}\text { Tim Produksi, } \\
\text { IE, QIP, dan } \\
\text { PTT }\end{array}$ & $\begin{array}{c}\text { Membuat } \\
\text { standar } \\
\text { maksimal WIP } \\
\text { di area kerja } \\
\end{array}$ \\
\hline
\end{tabular}

\section{Control}

Tahap kontrol merupakan tahap operasional terakhir dalam proyek peningkatan kualitas. Pada tahap ini, hasil-hasil peningkatan kualitas didokumentasikan dan disebar- 
Prosiding The 1st National Conference on Applied Business, Education, \& Technology (NCABET)"

Unversitas Bina Bangsa 2021

DOI Article : 10.46306/ncabet.v1i1.36

luaskan, praktik-praktik terbaik yang sukses dalam meningkatkan proses distandarisasikan dan disebar-luaskan, prosedur-prosedur didokumentasikan dan dijadikan pedoman prosedur kerja standar.

Tabel 4. Usulan Kontrol

\begin{tabular}{|c|c|c|c|}
\hline No. & $\begin{array}{c}\text { Kontrol yang } \\
\text { ada }\end{array}$ & $\begin{array}{c}\text { Tindakan Kontrol } \\
\text { saat ini }\end{array}$ & Usulan Kontrol \\
\hline 1 & $\begin{array}{l}\text { Belum ada visual } \\
\text { standar } \\
\text { maksimal WIP di } \\
\text { area kerja. }\end{array}$ & $\begin{array}{l}\text { Dibuatkan visual } \\
\text { standar maksimal WIP } \\
\text { di area kerja. }\end{array}$ & $\begin{array}{l}\text { Melakukan pengecekan dan } \\
\text { pengontrolan ketika proses produksi } \\
\text { berlangsung agar one pair flow berjalan } \\
\text { sesuai dengan visual yang telah ada di } \\
\text { area kerja, dan dilakukan dengan benar } \\
\text { oleh operator produksi. }\end{array}$ \\
\hline 2 & $\begin{array}{l}\text { Belum ada visual } \\
\text { sistem } \\
\text { pergantian sikat } \\
\text { di area proses } \\
\text { pengeleman. }\end{array}$ & $\begin{array}{l}\text { Dibuatkan visual sistem } \\
\text { pergantian sikat, dan } \\
\text { diletakkan di dekat area } \\
\text { proses pengeleman. }\end{array}$ & $\begin{array}{l}\text { Melakukan pengecekan dan kontrol } \\
\text { selama proses produksi berlangsung, dan } \\
\text { memastikan operator melakukan proses } \\
\text { sesuai dengan standar yang ada. }\end{array}$ \\
\hline 3 & $\begin{array}{l}\text { Operator belum } \\
\text { memahami SOP } \\
\text { yang ada. }\end{array}$ & $\begin{array}{l}\text { Dibuatkan SOP terbaru } \\
\text { di mana terdapat tanda } \\
\text { tangan operator sebagai } \\
\text { hasil latihan karena } \\
\text { telah memahami SOP } \\
\text { yang ada di area proses } \\
\text { masing-masing. }\end{array}$ & $\begin{array}{l}\text { Checksheet pengontrolan oleh } \\
\text { supervisor dan tim Quality yang dibuat } \\
\text { per-hari, sehigga bisa mengontrol bottle } \\
\text { neck pada proses dan produksi sehingga } \\
\text { secara cepat bisa melakukan corrective } \\
\text { action ketika terdapat finding issue di } \\
\text { area produksi. }\end{array}$ \\
\hline 4 & $\begin{array}{l}\text { Belum } \\
\text { berjalannya } \\
\text { weekly RCA } \\
\text { (root cause } \\
\text { analysis) di area } \\
\text { produksi. }\end{array}$ & $\begin{array}{l}\text { Menyediakan } r \text { board } \\
\text { meeting dengan format } \\
\text { RCA (root cause } \\
\text { analysis) di area } \\
\text { produksi sebagai } \\
\text { pendukung tier meeting } \\
\text { ketika ada issue di } \\
\text { produksi. }\end{array}$ & $\begin{array}{l}\text { Melakukan dokumentasi dan tracking } \\
\text { untuk setiap issue quality ataupun yang } \\
\text { lain setiap seminggu sekali, dan } \\
\text { melakukan action taken serta kontrol } \\
\text { setelahnya. }\end{array}$ \\
\hline
\end{tabular}


Prosiding The 1st National Conference on Applied Business, Education, \& Technology (NCABET)"

Unversitas Bina Bangsa 2021

DOI Article : 10.46306/ncabet.v1i1.36

Perbandingan penurunan cacat bonding sepatu di gedung 2 (dua) pada PT. Parkland

World Indonesia setelah menggunakan metode DMAIC pada periode Mei - Juli 2021

Tabel 4. Data Hasil Penurunan Cacat Bonding

\begin{tabular}{|l|c|c|c|c|}
\hline \multicolumn{1}{|c|}{ Bulan } & Jumlah Produksi & $\begin{array}{c}\text { Jumlah Cacat } \\
\text { Bonding }\end{array}$ & Satuan & Persentase \\
\hline April 2020 - Maret 2021 & 2.560 .580 & 59.598 & Prs & $2,33 \%$ \\
\hline Mei 2021 & 172.800 & 1.711 & Prs & $0,99 \%$ \\
\hline Juni 2021 & 218.400 & 1.679 & Prs & $0,77 \%$ \\
\hline Juli 2021 & 230.400 & 1.568 & Prs & $0,68 \%$ \\
\hline
\end{tabular}

Sumber : PT. Parkland World Indonesia

\section{KESIMPULAN DAN SARAN}

1. Teridentifikasi masih tingginya kecacatan pada saat produksi diantaranya bonding yang terjadi pada produk sepatu di gedung 2 mencapai $27.79 \%$ dari total cacat sepatu,.

2. Teridentifikasi bahwa yang menjadi penyebab terjadinya cacat bonding adalah operator tidak konsisten dalam proses lem upper ke outsole, pemakaian tooling tidak sesuai dengan SOP, aplikasi proses lem upper ke outsole kurang tebal dan tidak rata, dan yang terakhir terlalu banyak WIP di tempat kerja.

Berdasarkan kesimpulan diatas, maka saran yang diberikan penulis adalah agar penelitian selanjutnya mengambil rentang waktu penelitian yang lebih lama serta analisis lebih mendalam lagi.

\section{UCAPAN TERIMA KASIH}

Ucapan terima kasih atas kegiatan The $1^{\text {st }}$ National Conference on Applied Busines, Education, \& Technolody ( NCABET ) 2021 sehingga kami bisa ikut berpartisipasi dalam kegiatannya. Salam Motivasi.

\section{DAFTAR PUSTAKA}

Abdul Halim. 2000. Auditing. Yogyakarta: UPP AMP YKPN.

Amin, Syukron, dan Muhammad, Kholil. 2013. Six Sigma Quality For Business Improvement. Jakarta: Graha Ilmu.

Arini, D. (2004). Pengendalian Kualitas Statistik. Yogyakarta.

Assauri, Sofjan. (2004). Manajemen Operasi Dan Produksi. Jakarta : LP FE UI 
Prosiding The 1st National Conference on Applied Business, Education, \& Technology (NCABET)"

Unversitas Bina Bangsa 2021

DOI Article : 10.46306/ncabet.v1i1.36

Evans, Lindsay. 2007. Pengantar Six Sigma an Introduction to Six Sigma And Continuous Improvement. Jakarta. Salemba Empat.

Gasperz, Vincent. 2002. Pedoman Implementasi Program Six Sigma Terintegrasi dengan ISO 9001:2000, MBNQA, dan HACCP. Jakarta: PT Gramedia Utama.

Gasperz, V. (2003). Total Quality Management. Jakarta: PT. Gramedia Pustaka Utama

Gasperz, Vincent. 2006. Total Quality Management. PT. Gramedia Utama, Jakarta.

Gaspersz, V. (2011). Lean Six Sigma for Manufacturing and Service Industries. Bogor: Vinchristo Publication.

Ginting, Rosnani. 2007. Sistem Produksi. Yogyakarta: Graha Ilmu

Herjanto, Eddy. 2008. Manajemen Operasi Edisi Ketiga. Jakarta: Grasindo.

Ilie, G., \& Ciocoiu, C. N. (2010). Aplication of Fishbone Diagram to Determine The Risk With Multiple Causes. Management Research and Practice, 1-20.

Juran, J.M. and Frank M. Gryna: "Quality Planning and Analysis”, Third Edition, Mc Graw, New York, 1993.

Martono, Nanang. 2011. Metode Penelitian Kuantitatif. Jakarta: PT Raya Grafindo Persada.

Montgomery, D.C., 1998. Pengantar Pengendalian Kualitas Statistik. Gajah Mada.

Mulyadi. 2008. Sistem Akuntansi. Jakarta: Salemba Empat.

Prawirasentono, Suyadi, 2007, Filosofi Baru Tentang Mutu Terpadu. Edisi 2. Jakarta: Bumi Aksara

Ratnaningtyas, D.D., \& Surendro, K. (2013). Information qualify improvement model on hospital information system using six sigma. Procedia Technology, 9, 1166-1172.

Rahmad Kriyantono. 2006. Riset Komunikasi. Jakarta : Kencana Prenada Media Group.

Sugiyono. 2009. Metode Penelitian Kuantitatif, Kualitatif dan R\&D. Bandung : Alfabeta

Sugiyono. 2010. Metode Penelitian Pendidikan Kuantitatif, Kualitatif, R\&D. Bandung: Alfabeta

Sugiyono. (2017). Metode Penelitian Kuantitatif, Kualitatif, dan R\&D. Bandung : Alfabeta, CV.

T. Hani Handoko. Dasar-Dasar Manajemen Produksi dan Operasi, Edisi Pertama. BPFE. Yogyakarta,1999, hlm. 54.

Tannady, Hendy. (2015). Pengendalian Kualitas. Jakarta: Graha Ilmu. 